\title{
Episodic encephalopathy associated with thyroid disorders
}

\author{
D. C. THRUSH AND H. G. BODDIE \\ From the Regional Neurological Centre and Muscular Dystrophy Group Research Laboratories, \\ Newcastle General Hospital, Newcastle upon Tyne
}

SYNOPSIS Two patients with a thyroid disorder and an associated episodic encephalopathy are reported. The relationship between Hashimoto's thyroiditis, myxoedema, and neurological disease is considered, and the evidence for such disorders being due either to an underlying autoimmune process or that the encephalopathy is a direct result of the thyroid disorder is discussed.

During the past 30 years the neurological complications of thyroid disorders have become increasingly well recognized (Table). The purpose of this paper is to describe two patients in whom a thyroid disorder was associated with episodic encephalopathy, and to discuss the findings. The first patient developed episodic encephalopathy some time after a diagnosis of Hashimoto's thyroiditis had been made, and the second patient presented with episodic encephalopathy which improved with treatment of the associated myxoedema.

\section{CASE 1}

In 1967, D.H., a 37 year old housewife, presented with a two year history of an enlarging hard nodular goitre. Investigations showed that she was euthyroid but the erythrocyte sedimentation rate (ESR) was raised at $66 \mathrm{~mm}$ in the first hour, and thyroid antibodies were strongly positive (greater than $1: 2,000,000)$. A diagnosis of Hashimoto's thyroiditiso was made and treatment started with thyroxine $0 \cdot 1 \mathrm{mg}$ daily.

In April 1971 the patient became depressed for no apparent reason, and four months later was ado mitted to hospital having had three generalizeof attacks of myoclonus during a period of 15 minutes? She continued to have recurrent myoclonic episodes and, after three major seizures in $\mathbf{2 4}$ hours, was trans ferred to the Regional Neurological Centre for fur: ther assessment. The patient was pyrexial $\left(38.4^{\circ} \mathrm{C}\right)$ and unconscious but responded to painful stimuli. There was generalized hypertonia with the arms flexed and legs extended. The tendon reflexes were exaggerated and both plantar responses extensor. General examination showed no abnormality apart from an enlarged thyroid gland which was hard and nodular.

TABLE

NEUROLOGICAL COMPLICATIONS OF THYROID DISEASE

\begin{tabular}{|c|c|}
\hline Thyrotoxicosis & Myxoedema \\
\hline $\begin{array}{l}\text { 1. Myopathy (Ramsay, 1966) } \\
\text { 2. Exophthalmic ophthalmoplegia (Brain, 1959) } \\
\text { 3. Thyrotoxic crisis and coma (Mazzaferri and Skillman, 1969) } \\
\text { 4. Encephalopathy (Waldenström, 1945) } \\
\text { 5. Optic nerve lesions and retinopathy (Wagener, 1956) } \\
\text { 6. Choreoathetosis (Heffron and Eaton, 1970) } \\
\text { 7. Psychiatric disorders (Logothetis, 1961) } \\
\text { Associated disorders } \\
\text { 1. Myasthenia gravis (Engel, 1961b) } \\
\text { 2. Periodic paralysis (Engel, 1961a) }\end{array}$ & $\begin{array}{l}\text { 1. Dementia (Jellinek, 1962) } \\
\text { 2. Psychosis (Asher, 1949) } \\
\text { 3. Epilepsy (Evans, 1960) } \\
\text { 4. Coma (Forester, 1963) } \\
\text { 5. Cerebellar signs (Jellinek and Kelly, 1960) } \\
\text { 6. Cranial nerve abnormalities (Sanders, 1962) } \\
\text { 7. Peripheral neuropathy (Nickel et al., 1961) } \\
\text { 8. Carpal tunnel syndrome (Murray and Simpson, 1958) } \\
\text { 9. Myopathy (Norris and Panner, 1966) } \\
\text { 10. Pseudomyotonia and muscular hypertrophy (Wilson and Walton, } \\
\text { 1962) }\end{array}$ \\
\hline
\end{tabular}


Investigations showed an ESR of $88 \mathrm{~mm}$ in the first hour and a total white cell count of 29,900 per cu. $\mathrm{mm}$ (differential count normal). The serum proteins were $8.9 \mathrm{~g} / 100 \mathrm{ml}$, albumin $3.2 \mathrm{~g} / 100 \mathrm{ml}$, globulin $5.7 \mathrm{~g} / 100 \mathrm{ml}$, and electrophoresis showed an increase in the alpha and gamma globulin fractions. Immunoelectrophoresis showed an increase in immunoglobulins $\mathrm{A}, \mathrm{G}$, and $\mathrm{M}$. The cerebrospinal fluid was acellular with a protein of $130 \mathrm{mg} / 100 \mathrm{ml}$. An electroencephalogram on the day of admission showed no discernible cerebral activity but due to muscle artefact the gain used was only $56 \mu \mathrm{V} / \mathrm{cm}$. Normal investigations included blood urea and electrolytes, serum transaminases, cholesterol and uric acid, Wassermann reaction, screening for urinary porphyrins, viral antibodies, glucose tolerance test, latex test for rheumatoid arthritis, LE cells, culture of cerebrospinal fluid, and radiographs of chest and skull. The protein bound iodine was $6 \cdot 1 \mu \mathrm{g} / 100 \mathrm{ml},{ }^{131} \mathrm{I}$ uptake $14 \%$ in 24 hours, and the thyroid scan showed a multinodular goitre with patchy uptake of the isotope. Immunofluorescent screening tests for various antibodies were negative for antinuclear factor, mitochondrial, gastric parietal cell, and smooth muscle antibodies, but positive for thyroid colloid and cytoplasmic antibodies, and the tanned red cell agglutination test was positive to a titre of $1 / 25 \times 10^{5}$.

During the following three days, the patient became conscious but was confused and disorientated. Her level of consciousness continued to fluctuate markedly and she developed auditory and visual hallucinations. A brain scan $(99$ m-pertechnetate) showed ill-defined areas of increased uptake, and pneumoventriculography showed a small ventricular system of normal shape. After ventriculography her level of consciousness deteriorated and treatment was started with high doses of dexamethasone with progressive improvement though she remained hallucinated. Seven days after commencing dexamethasone there was a dramatic improvement and she became bright, alert, and orientated. After reduction of the dexamethasone, she relapsed into coma on two occasions with decorticate posturing of the limbs followed by a toxic confusional state. Two months after admission, the ESR was $8 \mathrm{~mm}$ per hour and the thyroid gland was smaller and softer. The patient was discharged from hospital on a maintenance dose of $8 \mathrm{mg}$ daily of dexamethasone.

When seen in the outpatient clinic two weeks later, the ESR had risen to $50 \mathrm{~mm}$ in the first hour, and the dexamethasone was increased to $12 \mathrm{mg}$ daily. Within a few days she developed a sore throat and lapsed into an acute confusional state associated with intermittent myoclonus of the limbs. The dexamethasone was increased to $20 \mathrm{mg}$ daily, and by the fifth day her mental state was normal. An electroencephalogram was diffusely abnormal and showed intermittent bursts of rhythmic delta activity and sharp wave discharges which recurred bilaterally and synchronously. The ESR fell from $120 \mathrm{~mm}$ on admission to $84 \mathrm{~mm}$ in the first hour, and the other investigations were as before. A subtotal thyroidectomy was performed (Professor Johnston) and histological examination confirmed the diagnosis of Hashimoto's thyroiditis.

As the patient had required large doses of dexamethasone to prevent relapses, treatment with cyclophosphamide was started and the dexamethasone dosage progressively reduced. Six days after her discharge from hospital she was readmitted in a confused state having had a grand mal convulsion. During the next 48 hours, her level of consciousness improved though again she experienced visual hallucinations. The ESR on admission was $126 \mathrm{~mm}$ and this progressively fell to $11 \mathrm{~mm}$ in the first hour.

The cyclophosphamide was increased to $100 \mathrm{mg}$ daily, since when she has felt much better. During the past year she has been admitted three times. On the first occasion, the ESR had risen to $84 \mathrm{~mm}$ per hour though she remained well, the second was precipitated by an upper respiratory tract infection, and the third followed a major seizure, on recovery from which she was confused and emotionally labile. During this latter illness the ESR fell from 50 to 8 $\mathrm{mm}$ in the first hour without an increase in the dexamethasone. Psychological assessment in June and December 1972 showed no evidence of intellectual deterioration or defect in short-term visual memory.

\section{CASE 2}

J.W., a 56 year old boilerman, had been well until four weeks before his admission to hospital in January 1971, when he developed a tremor of both hands. During the course of the next week he became unsteady and complained of generalized aches and pains. The patient remained in bed refusing to wash or shave and became progressively more irritable.

On admission, he was confused and showed a tendency to confabulate. A coarse tremor was evident in both arms, and there was generalized hypertonia and hyperreflexia. The plantar responses were flexor and there was no sensory deficit. General examination revealed no abnormality. Normal investigations including a full blood count, ESR, blood urea and electrolytes, Wassermann reaction, calcium, phosphate, alkaline phosphatase, cerebrospinal fluid, viral antibodies, and radiographs of chest and skull. Serum cholesterol was $210 \mathrm{mg} / 100 \mathrm{ml}$ and the serum 
transaminases were mildly elevated. An electroencephalogram showed a diffuse excess of slow activity and a brain scan ( $99 \mathrm{~m}$ pertechnetate) was abnormal showing a diffuse patchy uptake of the isotope.

Twenty-four hours after admission he became more confused and suddenly lost consciousness. During the next few hours there was a marked increase in muscular tone and both plantar responses were extensor. Bilateral carotid angiography showed a slow cerebral circulation but was otherwise normal. The patient was treated with dexamethasone with progressive improvement in his level of consciousness. A ventriculogram showed mild asymmetrical ventricular dilatation but was otherwise normal. Ten days after admission he improved dramatically, becoming fully conscious and orientated, though he remained amnesic for his recent illness. A repeat brain scan and electroencephalogram showed a marked improvement; the dexamethasone was tailed off, and he was discharged home. The diagnosis at this time was an acute encephalopathy of unknown aetiology.

Four weeks later he became withdrawn and complained of involuntary movements of the left arm. During the following week his speech became slurred and on the morning of admission (26 February 1971) he had a generalized convulsion. He was unconscious but reacted to noxious stimuli. There were roving eye movements but otherwise the cranial nerves were normal. Tone was markedly increased in all limbs, left more than right, and this was particularly pronounced in the arms which were flexed in a decorticate posture. The tendon reflexes were brisk and both plantar responses extensor.

Routine haematological, biochemical, and virological investigations were normal, as was the cerebrospinal fluid. An electroencephalogram showed non-specific abnormalities but several days later showed a marked deterioration with episodic generalized $1 / \mathrm{s}$ triphasic complexes and bursts of irregular slow activity at 3-4 Hz. A brain scan was normal and repeat ventriculography showed no new features.

Seventy-two hours after treatment with large doses of dexamethasone the patient was conscious and the tone in the limbs normal. However, over the next few days he became confused, restless, and had a grand mal convulsion. There was again gross hypertonia of all limbs, more marked on the left. Over the next few weeks despite a further relapse, he gradually improved and was discharged on dexamethasone and anticonvulsant therapy.

Three weeks later he was readmitted to hospital (13 April 1971) having become progressively bradykinetic and confused over a period of 36 hours. He was confused and disorientated and there was cog- wheel rigidity of all limbs, more marked in the arms. The dose of dexamethasone was increased and his mental state dramatically improved over the next 48 hours. Routine investigations showed no abnormalities but on this occasion the cerebrospinal fluid protein was raised at $88 \mathrm{mg} / 100 \mathrm{ml}$. An electroencephalogram showed diffuse slow activity which was more pronounced over the right hemisphere. He was discharged home one week later on a large maintenance dose of dexamethasone ( $2 \mathrm{mg}$ four times daily). During the next seven months he attended the outpatient department regularly and the dexamethasone was gradually reduced. During this time he remained well. Three days after his dexamethasone had been finally withdrawn he became inert and confused. Examination was similar to previous admissions. All investigations including serum ammonia levels were normal. As his presentation was similar to case 1 , the possibility was raised that his symptoms and signs were associated with a thyroid disorder. Immunofluorescent tests for antinuclear factor, gastric parietal cell, mitochondrial and smooth muscle antibodies were not detected but the thyroid cytoplasmic antibody was positive ando the tanned red cell agglutination test positive to a titre of $1 / 250$. Further tests of thyroid function showed that he was myxoedematous: ${ }^{131}$ I uptake $11 \%$ at 24 hours, thiopac-3/ value 124 (normal 92117 ), derived free thyroxine index 3.6 (normal 3.7 8.6 ) serum cholesterol $538 \mathrm{mg} / 100 \mathrm{ml}$., and protein bound iodine $1.0 \mu \mathrm{g} / 100 \mathrm{ml}$. Treatment was com menced with 1-thyroxine $0.1 \mathrm{mg}$ daily. During the past year the patient has felt much better, and has been readmitted on only two occasions for 24 hours when he complained of feeling 'off colour'.

\section{DISCUSSION}

The neurological illnesses described in these two patients with Hashimoto's thyroiditis and myxoedema were similar. Both patients suffered from recurrent attacks of an acute encephalopathy which were characterized by grand mal convulsions, a level of consciousness which varied from an organic confusional state to coma, and bilateral pyramidal tract signs with no localization. In addition, one patient experienced brief attacks of generalized myoclonus. Routine haematological, biochemical, and virological investigations were normal, and in both patients the raised cerebrospinal fluid protein, abnormal brain scans, and diffuse electroencephalographic abnormalities suggested a diffuse cerebral disorder. The encephalopathy appeared to improve 
with large doses of dexamethasone, and relapse when these were reduced. The first patient has improved on a combination of dexamethasone and cyclophosphamide, and the second after treatment of the associated myxoedema.

Apart from rare cases of myasthenia gravis (Daly and Jackson, 1964; Simpson, 1964; Singer and Sahay, 1966), the only other neurological illness associated with Hashimoto's thyroiditis is one case of encephalopathy (Brain et al., 1966). Their patient, a male aged 49 years, had been diagnosed as suffering from Hashimoto's thyroiditis with hypothyroidism some months before the onset of his neurological illness. Treatment with l-thyroxine had rendered him euthyroid. Over a period of a year, he suffered 12 strokelike episodes affecting different areas of the brain which were associated with protracted organic confusional states, a raised cerebrospinal fluid protein, and diffuse electroencephalographic abnormalities. Intensive investigations did not show any abnormality and various forms of treatment including prednisone and phenindione were ineffective. The encephalopathy remitted spontaneously, and five years after the onset, detailed clinical and psychometric tests were normal. It was thought that, while the sudden onset of repeated stroke-like episodes was suggestive of a vascular pathogenesis, the normal carotid angiography, failure to respond to anticoagulant therapy, and the evidence for a diffuse cerebral disorder-namely, the protracted confusional state associated with cerebrospinal fluid and electroencephalographic abnormalities-were against such a cause. The most likely explanation of the episodes was considered to be localized cerebral oedema, the relationship of which to the associated autoimmune disorder, Hashimoto's thyroiditis, was purely speculative. In many respects, the case reported is similar to our patient with Hashimoto's thyroiditis and encephalopathy, but there are some differences. The interval between the diagnosis of the thyroiditis and the onset of the encephalopathy was four years in our patient as opposed to a few months. At no stage of the illness did our patient show focal neurological signs, and she did appear to respond to treatment with large doses of dexamethasone. This latter difference may reflect no more than the use of a more potent corticosteroid given in a higher dosage.
Neurological complications of myxoedema include coma, which is frequently a terminal event. Such patients are usually overtly myxoedematous, often with a subnormal body temperature, and have progressed to a comatose state over a period of days. A review of the literature has not revealed any patient with myxoedema and an associated encephalopathy as seen in case 2, although Berris and Owen (1965) described a patient, a female aged 59 years, in whom myxoedema was diagnosed after two episodes of coma of sudden onset had occurred over a period of three years. However on both occasions the coma was associated with abnormally low serum sodium and chloride levels, and responded to treatment with saline. It is possible that the hyponatraemia was due to inappropriate secretion of antidiuretic hormone which has been reported in patients with myxoedema (Pettinger et al., 1964). Other factors which can be of importance in the pathophysiology of myxoedema coma include hypoxia, hypercapnoea, and hypopituitarism (Royce, 1971). None of these was present in either of our patients.

The aetiology and pathological basis of the encephalopathy in our two patients is obscure. It is generally accepted that myxoedema represents the end result of chronic thyroiditis (Hall, 1962), and that, although the aetiology of Hashimoto's thyroiditis is not fully known, there is evidence to suggest that it is a disorder secondary to an autoimmune process (Hall, 1962; Irvine, 1964). The presence of clinical features of more than one disorder thought to be due to autoimmune processes occurring in the same patient is well known, and Hashimoto's thyroiditis has been reported in association with other probable autoimmune disorders including myasthenia gravis (Simpson, 1960, 1964), pernicious anaemia (Tudhope and Wilson, 1960), rheumatoid arthritis (Buchanan et al., 1961), polymyositis (Sharvill, 1958), and systemic lupus erythematosus (White et al., 1961). If the encephalopathy and thyroiditis are clinical features of an underlying disorder of immune mechanisms, it is possible that an angiitis affecting the small cerebral blood vessels is the basis of the encephalopathy.

The aetiology of the encephalopathy in these patients remains in doubt. We think that, in case 1, the Hashimoto's thyroiditis and encephalo- 
pathy were manifestations of an underlying autoimmune disorder, whereas in case 2 the improvement in the encephalopathy after treatment of the myxoedema suggested that it was a direct complication of hypothyroidism. Nonetheless, the same mechanism could apply as in case 1 , in which instance the encephalopathy remitted spontaneously as reported in the case by Brain et al. (1966).

We wish to thank Dr. J. B. Foster and Dr. W. G. Bradley for permission to report these cases, and also for their helpful criticism in the preparation of this paper. We also thank Miss J. Booker for secretarial assistance. One of us (H.G.B.) is a holder of a Medical Research Council Research Registrarship.

\section{REFERENCES}

Asher, R. (1949). Myxoedematous madness. British Medical Journal, 2, 555-562.

Berris, B., and Owen, T. (1965). Unusual manifestations of myxedema. Canadian Medical Association Journal, 93, 2125.

Brain, Sir R. (1959). Pathogenesis and treatment of endocrine exophthalmos. Lancet, 1, 109-115.

Brain, Lord, Jellinek, E. H., and Ball, K. (1966). Hashimoto's disease and encephalopathy. Lancet, 2, 512-514.

Buchanan, W. W., Crooks, J., Alexander, W. D., Koutras, D. A., Wayne, E. J., and Gray, K. G. (1961). Association of Hashimoto's thyroiditis and rheumatoid arthritis. Lancet, 1, 245-248.

Daly, J. J., and Jackson, E. (1964). Case of Hashimoto's disease with myasthenia gravis. British Medical Journal, 1, 748.

Engel, A. G. (1961a). Thyroid function and periodic paralysis. American Journal of Medicine, 30, 327-333.

Engel, A. G. (1961b). Thyroid function and myasthenia gravis. Archives of Neurology (Chic.), 4, 663-674.

Evans, E. C. (1960). Neurologic complications of myxedema: convulsions. Annals of Internal Medicine, 52, 434-444.

Forester, C. F. (1963). Coma in myxedema. Archives of Internal Medicine, 111, 734-743.

Hall, R. (1962). Immunologic aspects of thyroid function. New England Journal of Medicine, 266, 1204-1211.

Heffron, W., and Eaton, R. P. (1970). Thyrotoxicosis presenting as choreoathetosis. Annals of Internal Medicine, 73, 425-428.

Irvine, W. J. (1964). Thyroid auto-immunity as a disorder of immunological tolerance. Quarterly Journal of Experimental Physiology, 49, 324-337.
Jellinek, E. H. (1962). Fits, faints, coma, and dementia in myxoedema. Lancet, 2, 1010-1012.

Jellinek, E. H., and Kelly, R. E. (1960). Cerebellar syndrome in myxoedema. Lancet, 2, 225-227.

Logothetis, J. (1961). Neurologic and muscular manifestations of hyperthyroidism. Archives of Neurology (Chic.), 5 , 533-544.

Mazzaferri, E. L., and Skillman, T. G. (1969). Thyroid storm. A review of 22 episodes with special emphasis on the use of guanethidine. Archives of Internal Medicine, 124, 684-690.

Murray, I. P. C., and Simpson, J. A. (1958). Acroparaesthesia in myxoedema. A clinical and electromyographic study. $\overrightarrow{\vec{D}}$ Lancet, 1, 1360-1363.

Nickel, S. N., Frame, B., Bebin, J., Tourtellotte, W. W., Parker, J. A., and Hughes, B. R. (1961). Myxedema neuropathy and myopathy. Neurology (Minneap.), 11, 125-137.

Norris, F. H., Jr., and Panner, B. J. (1966). Hypothyroid myopathy. Archives of Neurology (Chic.), 14, 574-589.

Pettinger, W. A., Talner, L., and Ferris, T. F. (1965). In- $\vec{O}$ appropriate secretion of antidiuretic hormone due to myxedema. New England Journal of Medicine, 272, 362- $\vec{\omega}$ 364.

Ramsay, I. D. (1966). Muscle dysfunction in hyperthyroidism. Lancet, 2, 931-935.

Royce, P. C. (1971). Severely impaired consciousness in? myxedema-a review. American Journal of Medical Sciences, 261, 46-50.

Sanders, V. (1962). Neurologic manifestations of myxedema. New England Journal of Medicine, 266, 599-603.

Sharvill, D. (1958). Polymyositis and thyroiditis. Proceedings of the Royal Society of Medicine, 51, 934.

Simpson, J. A. (1960). Myasthenia gravis: a new hypothes Scottish Medical Journal, 5, 419-436.

Simpson, J. A. (1964). Immunological disturbances 船 myasthenia gravis with a report of Hashimoto's disease developing after thymectomy. Journal of Neurolog; Neurosurgery, and Psychiatry, 27, 485-492.

Singer, W., and Sahay, B. M. (1966). Myasthenia gravì;, Hashimoto's thyroiditis, and pernicious anaemia. British Medical Journal, 1, 904.

Tudhope, G. R., and Wilson, G. M. (1960). Anaemia in hypothyroidism. Quarterly Journal of Medicine, 29, 513537.

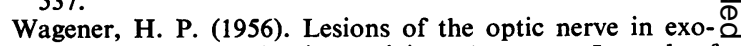
phthalmos of endocrine origin. American Journal of $\overrightarrow{\vec{F}}$ Medical Sciences, 232, 226-239.

Waldenström, J. (1945). Acute thyrotoxic encephalo- or myopathy, its cause and treatment. Acta Medica Scandinavica, 121, 251-294.

White, R. G., Bass, B. H., and Williams, E. (1961). Lymphadenoid goitre and the syndrome of systemic lupus erythematosus. Lancet, 1, 368-373.

Wilson, J., and Walton, J. N. (1959). Some muscular mani-C festations of hypothyroidism. Journal of Neurology, Neurosurgery, and Psychiatry, 22, 320-324. 